\title{
Copper(I)-Senelenophene-2-carboxylate Catalyzed Cross- Coupling of Aryl or alkyl Thiols And Aryl Halides
}

\author{
Vanessa Lóren Nunes, ${ }^{(\mathrm{PG})}$ Ingryd Cristina de Oliveira ${ }^{(\mathrm{IC})}$ and Olga S. do Rêgo \\ Barros $^{(P Q) *}$
}

\author{
Instituto de Química, Universidade Federal de Goiás -UFG, Campus Samambaia, 74001-970-Goiânia-GO \\ - Brazil.*olgarb@quimica.ufg.br
}

Keywords: thiols, carbon-sulfur bond, copper

\section{INTRODUCTION}

Aryl sulfides are important building blocks in organic synthesis since many pharmaceutical compounds have the prevalence of the C-S bond. ${ }^{1}$ Transitionmetal catalyzing cross-coupling reactions between Csp ${ }^{2}$-centers have been extensively used for preparing pharmaceuticals and agrochemical intermediates. ${ }^{2}$ Considering the advantages of using copper catalysts, less expensive and toxic than palladium salts, we investigated a new methodology to build a carbon-sulfur bond, without any ligand or co-catalyst. In this way, we present our first results of a copper(I)-senelenophene-2-carboxylate (CuSC) catalyzed cross-coupling reaction between aryl halides and thiols.

\section{RESULTS AND DISCUSSION}

The CuSC can be easily prepared from selenophene-2-carboxylic acid and $\mathrm{Cu}_{2} \mathrm{O}$ upon heating in toluene (Scheme 1). The obtained product is air-stable powder, which can be stored and handled at room temperature without any special precautions. $^{3}$

Scheme 1. Preparation of CuSC.

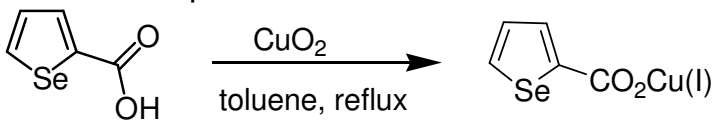

Our initial studies have focused on the development of an optimum set of reaction conditions, in order to optimize the reaction conditions. In this way, aryl iodide $(1.0 \mathrm{mmol}), 2$-methybenzenethiol $(0.5 \mathrm{mmol})$ and CuSC $(0.1 \mathrm{mmol})$ were treated with different bases, solvents, temperatures and different reaction times. We found that the use of CuSC (10 mol \%), DMSO (3 mL), 1a $(1.0 \mathrm{mmol})$, the appropriate thiol $(0.5 \mathrm{~mol})$, and $\mathrm{K}_{3} \mathrm{PO}_{4}(2.0 \mathrm{mmol})$ at reflux $\left(130^{\circ} \mathrm{C}\right)$ was optimal. This condition was subsequently applied to other substrates and the results are summarized in Table 1. The inspection of Table 1 shows that the reaction worked well for a variety of aryl iodides and bromides. It should be pointed out that aryl substituted and alkyl thiols were compatible with the reaction conditions.

Scheme 2.Cross-coupling reactions.

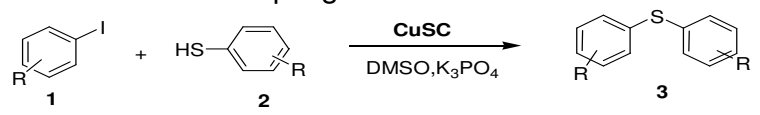

Table 1. CuSC Cross-Coupling of Aryl or alkyl Thiols And Aryl Halides.

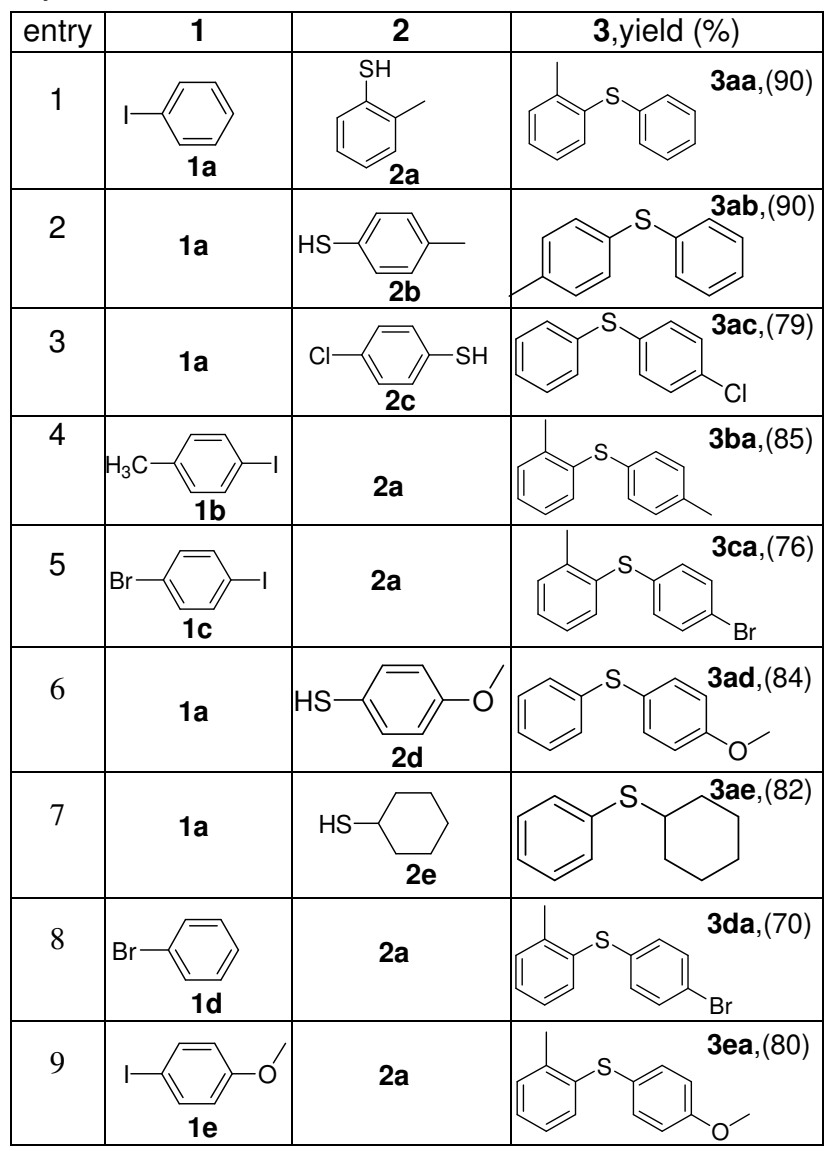

\section{CONCLUSION}

In summary, we established a new and efficient route to prepare aryl sulfides in good yields via catalyzed cross-coupling reactions of thiols, aryl iodides and cheap and environmentally friendly CuSC.

\section{ACKNOWLEDGEMENTS}

We are grateful to UFG, IQ and CNPq by the grant of the scholarship for Nunes, V.L.

\section{REFERENCES}

${ }^{1}$ Itoh, T.; Mase, T. Org. Lett. 2004, 6, 4587-4590.

2Kwong, F. Y.; Buchwald, S. L. Org. Lett. 2002, 4, 3517-3520. 3Innitzer, A.; Synlett 2005, 2405-2406 